\title{
From Me to We and Back Again: Creating Health System Transformation through Authentic Collaboration within and beyond Nursing
}

\author{
Annette Elliott Rose, RN, MN, PhD(c) \\ Research Trainee, WHO Collaborating Centre on Health Workforce Planning and Research \\ School of Nursing, Dalhousie University \\ Perinatal Nurse Consultant, Reproductive Care Program of Nova Scotia, \\ Halifax, NS

\section{Kelly Lackie, RN, BScN, MN, PhD(c)} \\ Faculty/Interprofessional Education Lead, \\ RN Professional Development Centre, \\ Research Trainee, WHO/PAHO Collaborating Centre for Health Workforce Planning \\ and Research \\ Dalhousie University, Halifax, NS
}

"A boat doesn't go forward if everyone is rowing their own way."

More than 10 years after the Romanow Report (2002), other national reports continue to echo the call for change in health system design and delivery - specifically, the call for collaborative practice that responds to healthcare needs while attending to value, sustainability and improved outcomes. Despite increased financial investments in healthcare, Canada is lagging in its ability to provide care that promotes gains in health status (Health Council of Canada 2013). Why is this so? Is it because the care that is provided is disjointed? Or that care is organized and delivered in a way that meets providers' needs rather than people's needs? Or is it because the context in which healthcare providers are educated, and in which they work, has not evolved to support change? These are difficult questions to answer.

Recent reports on nursing education and role optimization (CNA 2012; MacMillan 2013) recommend strengthened partnerships between education and practice so that academic institutions prepare nurses differently and practice settings adapt to support those changes. They also call upon nurses to become vocal and visible about their unique contributions within the healthcare team. 
Transforming ourselves is crucial if we want to transform the health system to meet people's health needs and improve outcomes - for patients and families, for providers and for the system (Tomblin Murphy 2007). Given that health system transformation is a daunting task for formal healthcare leaders and decisionmakers, it is not surprising that individual nurses find it a formidable challenge to create, support and lead health system transformation.

A common thread in current thinking about health system transformation is the need to work together, at all levels, to create and support a high-performing health system (Ross-Baker et al. 2008). At the level of the individual healthcare provider, team members must understand their own unique contributions, other members' contributions and how we mesh these parts together to create a shared vision for improved outcomes.

Many registered nurses express frustration and confusion about RNs' scope of practice and their place within the interprofessional team. These feelings have proliferated with the advent of new healthcare provider roles and with the evolution of inter-professional collaborative practice. Some nurses no longer know where they belong or what is expected of them.

These feelings are not surprising. Historically, healthcare providers have been educated within specific homogeneous professional groups, with minimal integration with other professionals, making it difficult for those from different disciplines to appreciate the expertise, roles, responsibilities and philosophical perspectives of other provider groups (Schwartz et al. 2011). As a result, many healthcare providers become "professionalized," forming stereotypical ideas about their own role and the roles of others. These beliefs can lead to territorial behaviours, conflict and team ineffectiveness, ultimately affecting their willingness to collaborate with others (Axelsson and Axelsson 2009; Hall 2005). These beliefs are compounded by the misperception that nurses need to be all things to all people. With the introduction of new healthcare providers and the advancement of others' roles, nurses may feel that their "turf" is being encroached upon and that there may no longer be a need for them in the healthcare system. But nothing could be farther from the truth. Nurses have the potential to be an indomitable force in health system transformation.

What is needed is a sound understanding of what inter-professional collaboration is and how to actualize it in our everyday experiences.

If we listen carefully to the public, they tell us that they want us to work together more effectively - to create seamless communication and clear integration of care 
across health sectors. This requires a fundamental shift in how we are educated and how we organize and deliver healthcare, a shift that comprises such difficult topics as healthcare provider compensation, issues of professionalization and the need to move from provider-centred to truly patient-centred care. Many healthcare providers, including nurses, claim to work in inter-professional collaborative teams, when in fact they practise within multidisciplinary teams. But merely working alongside other healthcare providers does not constitute working collaboratively. Multidisciplinary teams typically have designated leaders, members with distinct and independent professional roles and non-consensual decision-making, and they place little emphasis on team process (Sheehan et al. 2007). In contrast, in an inter-professional collaborative team, members integrate their efforts, competence and skills to work towards a common goal; leadership is shared, and team members strive to improve team functioning (Bridges et al. 2011; Lackie and Banfield 2009; Oandasan and Reeves 2005).

Authentic collaboration is an emergent activity fuelled by shared decisionmaking, collective leadership and engagement among healthcare providers - and more importantly, with patients and families (Canadian Interprofessional Health Collaborative 2010; Ellerby et al. 2010). When teams collaborate authentically, healthcare provider engagement is based upon individual and shared competencies and scope of practice, rather than on professional title alone. When healthcare providers with complementary skills and expertise collaborate authentically, creative solutions to patient care unfold (Zwarenstein et al. 2009).

\section{Authentic Collaboration: Eight Lessons Learned}

Here are eight steps that individual nurses can take to help shift individual or multidisciplinary approaches towards authentic collaboration.

\section{Listen with intention and attention - to everyone's stories and to your own.}

Be reflective: Know your own story, how to articulate your scope of practice and what you bring to the healthcare team. Start by taking the "30/3/30 Challenge" (see box).

2. Find your passion. There are many opportunities in nursing and in healthcare; choose the path that lights your fire and keeps it burning. Stand true to the philosophical tenets that inspired you to become a nurse, and recognize that everyone on the healthcare team has similar aspirations. The journey is yours you are responsible for finding meaning and happiness in your nursing career.

3. Build relationships. Regardless of our field of practice, nurses need to work and learn with, from and about our colleagues from across the health and social sectors. Doing so builds mutual understanding and common vision that views health through a broader lens, with attention to the social determinants of health. 
The 30/3/30 Challenge

Imagine yourself with a nursing colleague. Be ready to (a) introduce yourself and clearly articulate your scope of practice (30 seconds); (b) articulate your contributions to the healthcare team (3 minutes); and (c) introduce and explain an issue and why it is important, and share a solution to the issue (30 minutes).

After you have mastered this exercise with a nursing colleague, try having this conversation with a non-nursing colleague. The intention is for you to become comfortable articulating who you are, what you offer and your thoughts on a health system issue. This approach creates visibility and opportunities for nurses to effect health system transformation.

4. Be a role model and a mentor. Seek out role models and mentors, and not only within the nursing profession. The moments we share with others often make a difference, leaving lasting impressions and profoundly changing the direction of our career or someone else's (Ryan et al. 2010).

5. Think outside the box. If you could recreate healthcare in Canada, what would it look like - the healthcare team, and nurses' roles within it? Be able to articulate clearly what you offer and how you are prepared to extend and re-create your role to meet the needs and improve the outcomes of patients and families. Try to come to the table with some creative solutions for change.

6. Be inquisitive, and question everything. Asking questions is sometimes tough, depending on the forum and the perceived or actual differences in power in the room. A good approach is to open with a request for more information: "Just to clarify..." or "For my own learning..." If you come to the encounter knowing and articulating your own unique contributions, with an open attitude of understanding and possibility and with a focus on improving patient care, you may enlighten both yourself and your colleagues.

7. Be knowledgeable, and maintain that knowledge. Evidence-informed practice is not just a buzzword. It makes a difference in health, provider and system outcomes, and in how nurses participate fully as team members. We have a professional commitment to lifelong learning that requires us to actively seek out knowledge. This is key to optimizing nursing expertise.

8. Embrace and support your nursing community. Recognize and celebrate your colleagues - in research, practice, administration and education. Offer respect, kindness, praise and encouragement. We all have something to contribute and something to learn from one another.

\section{Acknowledgements}

The authors would like to thank their colleague and doctoral supervisor, Dr. Gail Tomblin Murphy, for her valuable review, insights and support, and Dr. John Gilbert, Professor Emeritus, University of British Columbia, from whom we adapted the 30/3/30 Challenge. 


\section{References}

Axelsson, S.B. and R. Axelsson. 2009. "From Territoriality to Altruism in Interprofessional Collaboration and Leadership." Journal of Interprofessional Care 23(4): 320-30.

Bridges, D.R., R. Davidson, P. Odegard, I. Maki and J. Tomkowiak. 2011. "Interprofessional Collaboration: Three Best Practice Models of Interprofessional Education." Medical Education Online 16: 1-10.

Canadian Interprofessional Health Collaborative. 2010. A National Interprofessional Competency Framework. Retrieved February 21, 2014.<http://www.cihc.ca/files/CIHC_IPCompetencies_ Feb1210.pdf $>$.

Canadian Nurses Association (CNA). 2012. A Nursing Call to Action: The Health of Our Nation, the Future of Our Health System. Retrieved February 21, 2014. < http://www.cna-aiic.ca/ /media/cna/ files/en/nec_report_e.pdf>.

Canadian Nurses Association (CNA). 2014. The Practice of Nursing. Retrieved February 21, 2014. $<$ http://www.cna-aiic.ca/en/becoming-an-rn/the-practice-of-nursing $>$.

Ellerby, N., A. Lockwood, G. Palin, S. Ralphs and B. Taylor. 2010. Working Relationships for the 21st Century: A Guide for Authentic Collaboration. Retrieved February 21, 2014. <http://www.oasishumanrelations.org.uk/resources/books/a-guide-to-authentic-collaboration>.

Hall, P. 2005. "Interprofessional Teamwork: Professional Cultures as Barriers." Journal of Interprofessional Care (Suppl. 1): 188-96.

Health Council of Canada. 2013. Better Health, Better Care, Better Value for All. Refocusing Health Care Reform in Canada. Retrieved February 21, 2014. <http://healthcouncilcanada.ca/rpt_det_gen. php?id=773\&rf $=2>$.

Lackie, K. and V. Banfield. 2009. "Interprofessional Education and Collaborative Practice: Powerful Strategies to Promote Effective Team and Client Relationships in Nova Scotia." Nursing in Focus 10(2): 18-19.

MacMillan, K., ed. 2013. Proceedings of a Think Tank on the Future of Undergraduate Nursing Education in Canada. Halifax: Dalhousie University School of Nursing.

Oandasan, I. and S. Reeves. 2005. "Key Elements for Interprofessional Education. Part 1: The Learner, the Educator and the Learning Context." Journal of Interprofessional Care (Suppl. 1): 21-38.

Romanow, R. 2002. Building on Values: The Future of Health Care in Canada - Final Report. Commission on the Future of Health Care in Canada. Retrieved February 21, 2014. <http://publications.gc.ca/pub?id $=237274 \& s l=0>$.

Ross-Baker, G., A. McIntosh-Murray, C. Porchellato, L. Dionne, K. Stelmakovich and K. Born. 2008. High Performing Healthcare Systems. Delivering Quality by Design. Toronto: Longwoods.

Ryan, A., L. Goldberg and J. Evans. 2010. "Wise Women: Mentoring as Relational Learning in Perinatal Nursing Practice." Journal of Clinical Nursing 19(1-2): 183-91.

Sheehan, D., L. Robertson and T. Ormond. 2007. "Comparison of Language Used and Patterns of Communication in Interprofessional and Multidisciplinary Teams." Journal of Interprofessional Care 21(1): 17-30.

Schwartz, L., D. Wright and M. Lavoie-Tremblay. 2011. "New Nurses' Experience of Their Role within the Interprofessional Health Care Teams in Mental Health." Archives of Psychiatric Nursing 25(3): 153-63.

Tomblin Murphy, G. 2007. A Framework for Collaborative Pan-Canadian Health Human Resources Planning. Appendix: Example of a Conceptual Model for HHR Planning. Retrieved February 21, 2014. $<$ http://www.hc-sc.gc.ca/hcs-sss/pubs/hhrhs/2007-frame-cadre/app-ann-eng.php>.

Zwarenstein, M., J. Goldman and S. Reeves. 2009. "Interprofessional Collaboration: Effects of Practice-Based Interventions on Professional Practice and Healthcare Outcomes." Cochrane Database Systematic Review 3: CD000072. 